\title{
A Liberal Arts Approach to Teaching Robotics
}

\author{
Ann Wright, Gabriel Ferrer, Andrew Wright \\ Hendrix College/University of Arkansas at Little Rock
}

1. Introduction

A new natural science course is under development at Hendrix College. The course is titled "Robotics Exploration Studio" and will be aimed at the non-science major liberal arts student. There will be no pre-requisites for this course. The course will utilize Lego bricks and Technic parts for mechanical components and the Lego Mindstorm ${ }^{1}$ programmable RCX brick as a platform for programming.

Hendrix College is a private, residential, co-educational, undergraduate institution of the liberal arts affiliated with the United Methodist Church. It is located in Conway, Arkansas, approximately thirty miles northwest of Little Rock. Hendrix currently has a student body of 1057 students from 35 states and 12 foreign countries. The faculty has 85 full-time members and 17 part-time members. The student to faculty ratio is 13 to 1 , with an average class size of 15 students.

Hendrix College switched from a trimester system to a semester system starting in Fall 2002. Due to the switch, a complete renovation of the core curriculum requirements for graduation was implemented. The new robotics course would help satisfy the natural science inquiry learning domain. The 2002-2003 Hendrix Catalog ${ }^{2}$ describes the natural science learning domain in the following way:

"Science and Technology are playing an ever-increasing role in our society. In order to navigate this sea of information, students must know and understand how science does and does not work, the application of scientific and mathematical principles, and the distinction between science and dogma. This requires the coupling of basic scientific principles with systematic, critical analysis. Emphasis is on the methods used to model, gather, interpret, and evaluate data critically, and the placement of this information into a larger context. In the face of our rapidly evolving understanding of the natural world, application of the scientific method is an enduring skill for assessing the validity of observations related to the natural world. This mode of inquiry inextricably links course content and the analysis process."

The new natural science requirement is composed of two courses from different departments that are designated as natural science courses, one of which must have a laboratory component. The faculty believed that students needed the experience of 
actually doing science as well as learning about science. There are presently two biology courses, one chemistry course, and six physics courses that are classified as natural science laboratory courses. Five of the nine courses have no pre-requisites. All but one of the nine courses are geared toward science majors. There is a clear need in the curriculum for a natural science laboratory course that is geared towards the non-science major, has no prerequisites, and is attractive to students from various backgrounds.

2. The course models

Our model course is Robotic Design Studio taught at Wellesley College by Dr. Franklyn Turbak and Dr. Robert Berg. Wellesley is a private liberal arts, all-female college in Massachusetts. The course has no pre-requisites and is aimed at the non-science major. Wellesley received an NSF grant (NSF DUE-9650969) in 1996 to develop this course. The Wellesley course has been taught for seven years, and results have been documented ${ }^{3,4}$.

The Wellesley course has the following goals:

- Accessibility: Make the course accessible to all students; approachable for students with no technical background, interesting for students with a technical background

- "Do" engineering, not just study it

- Creativity of expression

The course meets for 12 four-hour sessions over a 3.5 week January session. The first half of the course is composed of a series of design challenges that build skills in robot programming and mechanical design. In the second half of the course, the students design and build a robot from scratch. All construction is done using Lego bricks. The CPU is a Motorola $68 \mathrm{HC} 11$ mounted on a Handy Board ${ }^{5}$ programmed in Logo.

The design challenges include:

- Given a constructed, preprogrammed robot, determine how its programming works and modify that program to give the robot new behaviors

- Build an interactive "kinetic sculpture" to gain an understanding of how the different Lego parts interact

- Build an "indestructible box" that can survive a six-foot fall without breaking apart

- Learn about gearing by building a drag racer that carries a $1 \mathrm{~kg}$ mass.

The second half of the course is deliberately open-ended. Students design a robot to perform any task they like. At the conclusion of the course, students show off their creations in a robot exhibition.

The principal means of student evaluation in the course are design journals. Each student keeps a journal of her experience in the course and development of her project. The students design web pages detailing their final projects.

The Wellesley course is a good model for a Lego-based robotics course at Hendrix 
College because of the similarities in environment and target student population. Both courses are aimed at the non-science major, liberal arts student. The final designs are displayed in an exhibition rather than a competition. This allows for more creative range of designs and a reduction in stressful environment during the class. The course has many great ideas for introductory design projects that we will implement in our course.

The University of Arkansas at Little Rock (UALR) has two courses, both taught by Dr. Andrew Wright, that are applicable to the new Hendrix College course. The first course of interest is Introduction to Engineering Analysis and Design (SYEN 1305) ${ }^{6}$. This course was designed for first-year systems engineering students. The course content includes introductory design theory, reverse engineering, and a small Lego robot design contest. The design contest uses the problem of a robot climbing over a hill and delivering whiffle balls to a goal to illustrate the value of analysis in design. Basic statics for rolling vehicles is covered and a relationship for non-slip rolling on the hill is derived. The key parameters in the relationship include vehicle mass, coefficient of friction, gear ratio, wheel radius, and motor torque. The students have to make choices from the constrained set of parts presented by the Lego kit. This constraint provides a finite, discrete set of alternatives. Only a small subset of these values will solve the problem. Many of the solutions are counter-intuitive and cannot be reached without analysis.

The second UALR course of interest is called FIRST in Engineering. FIRST stands for "For the Inspiration and Recognition of Science and Technology". FIRST sponsors an annual robotics competition for high school students and a Lego League competition for younger students. FIRST in Engineering is a service-learning based course, designed to train college engineering students at the junior and senior level in higher level mechanical design skills. The service component of this course occurs when the college students transfer the knowledge in training sessions for high-school team members. The course development has been presented at the 2002 American Society of Engineering Education (ASEE) meeting ${ }^{8}$. The course was taught for the first time during Fall 2002 and results will be presented at the 2003 ASEE meeting in Nashville, TN.

There are several other courses from which to draw resources and ideas. The Swarthmore College course, entitled "Building Intelligent Robots", is an introduction to both computer science and artificial intelligence. This course uses the $\mathrm{C}$ programming language. Students read and discuss research papers from the literature in addition to the laboratory experience of robot building and programming. In the Hendrix course, we plan to emphasize issues in robot construction to a greater degree, leaving less time for in-depth readings from the robotics literature. We also intend to emphasize the relationship between reactive and traditional symbolic artificial intelligence in our projects, as opposed to the machine learning issues emphasized at Swarthmore College.

There are robotics contest courses at engineering schools such as Rice (ELEC 201) ${ }^{10}$ and MIT (6.270) ${ }^{11}$. These courses are open to non-science majors. However, there are many engineering students in these courses. While these courses can be used for inspiration and motivation, the courses are geared toward the engineering student. The liberal arts student 
with no engineering background will need a different approach.

\section{The Hendrix College course}

The Wellesley course will need to be adapted to meet the needs of Hendrix College. The main difference will be that the Hendrix course will be scheduled during the academic year. The main restraint for Wellesley to produce a regularly scheduled class is the lack of dedicated laboratory space. Hendrix College has just built a new science facility, and has dedicated a room for this robotics course. Another change will be in the programming details. At the time of the Wellesley course development, the best programming platform was "Handy Boards". Since 1996, Lego has produced the Lego Mindstorms package, which includes the programmable RCX brick. BrickOS ${ }^{12}$ (formerly LegOS) is an operating system based on the Linux kernel that allows the user to program in $\mathrm{C}$ or $\mathrm{C}++$. There have also been developments in using Java programming language to program the RCX bricks $^{13}$. Since the Hendrix course will take place over a standard length semester, there will be time for more instruction of physical principles, programming skills, and new topics such as robotics in literature and the basics of artificial intelligence.

The new Hendrix course will have several small design assignments, culminating in a large assignment at the end of the course. The final project will be displayed at an exhibition open to the Hendrix community and documented on student-generated web pages. The course will be presented annually starting in Fall 2003.

There will be no course prerequisites. A mathematics competency in algebra will be assumed. The geometry and trigonometry needed for discussing vectors and forces will be covered in class. All mechanics will be taught as algebra-based, as is done in the General Physics I class (PHYS 210) at Hendrix College ${ }^{2}$. No prior experience in computer programming will be assumed.

The primary material presented will be basic skills in mechanical design and computer programming. Methods of scientific reasoning, the epistemological basis of scientific claims, and the difference between the hypothesized and observed behavior of a physical system will also be major themes. The students will also have to develop significant teamwork skills to be successful in the course. The Lego kits will be used to create the mechanical aspects of the robots, and the programming will be accomplished using Java and the Lego RCX programmable brick.

While it will not be possible to provide a complete education in mechanical dynamics and statics, students will be taught the basic physical concepts necessary to make good design decisions. The concept of vectors will be important in the discussion of forces and momentum. Newton's Laws will be introduced and some basic applications such as pulleys, inclined planes, and friction will be used as examples.

Since the simplest robots are wheeled vehicles, the basic physics of rotational motion and torque will be introduced. The applications of gears will also be a primary topic. Other 
topics will include motors, motor mountings, and steering configurations.

One of the main motivations for the student will be to get their robot to accomplish a task or navigate an obstacle. It will be necessary for the student to understand and use several sensors such as rotation, touch, and light sensors. Also, it will be necessary to measure and evaluate such physical properties as velocity, acceleration, and power. Robots provide an exciting opportunity to truly motivate the student to understand these key physical concepts.

The design process will be discussed and used daily in the classroom sessions and laboratory exercises. The steps of prototyping, brainstorming, reverse engineering, and writing technical reports will be discussed and employed.

The computer science objective of this course is to introduce students to concepts from artificial intelligence that are of value in programming simple robots. This course is not intended to prepare students for later courses in programming. Students will be provided with a library of code to be used for writing robot control programs.

Students will write robot programs inspired by the reactive model of Brooks ${ }^{14}$. The activity of a robot will be modeled as a function that maps a domain (its sensors) to a range (its effectors). The command sent to each effector will be a mathematical function of the values of its sensors. Each collection of such functions is called a behavior.

Inspired by Brill ${ }^{15}$ et al, a robot's memory will also be considered as a sensor input and updated as if it were an effector. These memories are called markers. They can store previous sensor values, counters, times, or position coordinates.

A significant advantage of this approach is that no explicit looping is required in order to implement robot behaviors. The values of each effector are determined on every system time-step by invoking the appropriate functions. This will simplify the task of teaching the students enough programming to program a robot.

Interesting robot programs often require a sequencing of distinct behaviors. One means of sequencing behaviors is to create a $\operatorname{plan}^{16}$. For example, when a robot is delivering an object to its destination, one behavior can guide the robot to the destination, while another behavior takes over when the destination is reached in order to deliver the object. This is an example of a two-step plan.

In many situations, human-generated plans may suffice. In other situations, plans can be automatically generated using a planner. In this course, students will use a planner that can generate plans for simple navigation problems in polynomial time.

Students will program the RCX using the Java programming language. An open-source version of the Java Virtual Machine called leJOS ${ }^{13}$ is freely available and widely used. Significant infrastructure will be provided to the students in order to minimize the subset 
of the Java language that they must learn.

The following are examples of introductory design and programming exercises that will help to introduce the concepts for this class.

- Hill-climber: The concepts of vectors, friction, torque, and gear ratios can be demonstrated by building a robot that can climb a steep incline.

- Aimless wanderer: Drives straight for a while, then turns randomly

- Obstacle avoider: Similar to aimless wanderer. If it hits something, it backs up a short distance and picks a new direction

- Flashlight follower: Wanders aimlessly if no light sensed. Drives straight as long as light is sensed

- Tag: Two robots; one robot is "it", "it" tries to tag the other robot. Once tagged, the other robot is "it"

- Simple Delivery: Robot finds a pre-assigned object and delivers it to a pre-assigned location

- Complex Delivery: Robot follows a plan for finding several objects and delivering them to several locations

The course grade will be determined by several factors. A design journal will be completed by each student. This journal will be the primary tool for evaluation of a student's individual effort and accomplishment. After each design project, the team of students will present a written project report. The final, creative design project will require a written report, a web-site, and an oral presentation at an open exhibition.

4. The liberal arts student

The following examples are specific goals for a liberally educated student:

- Cognizant application of the scientific method

- An intuitive understanding of the physical world

- Application of mathematics to real-world problems

- An understanding of computers and programming

One drawback found in traditional science courses is that there is very little hands-on, discovery-based learning, even in laboratory courses. Typically, students are told exactly what to do, when to do it, how to analyze the results, and what the answer should be.

Several universities and colleges have begun to address the drawbacks of traditional laboratory experiences through the use of a robotics design studio class or competition. In a robotics design class, students are motivated to learn the physical concepts necessary to understand why their robot will or will not do the tasks assigned. For example, a student will be very interested to learn how a gear can make a robot faster if he knows he will be racing against his fellow students' robots. We will foster an atmosphere of exploration by providing the necessary background theory, necessary tools and materials, and letting the 
students find the correct answer through educated trial and error. In this way, the scientific method is not just a theory, it is a guide for success.

Students will employ the scientific method explicitly and interactively. They will write explicit hypotheses about the expected behavior of their creations in their design journals, and will then observe whether the behavior of their robots conforms to their hypotheses. Students will be responsible for testing their robots repeatedly in order to build confidence in the veracity of their hypotheses.

It is widely known that large numbers of liberal arts students find science intimidating. The construction of working robots provides an outstanding opportunity for liberal arts students to connect the abstract world of Newtonian mechanics to the real, physical world they inhabit. Constructing hypotheses of expected system behavior will require students to relate the abstract concepts of mechanics to real events that they will witness. These physical design exercises will demonstrate the relevance of abstractions such as algebra and trigonometry to real problems in the real world.

Through writing simple programs to control their robots, liberal arts students will learn and experience the fundamental underlying ontology of computer programming; namely, that a computer program receives inputs that are deterministically transformed into outputs. They will also have the opportunity to learn some of the essentials of artificial intelligence without having to complete the large number of computer science prerequisites that are often necessary for taking an artificial intelligence course. Students who are curious about AI can gain a sense of its technical basis and capabilities without more than a one-semester time investment.

Robotics is one way to address each of the goals listed above and also engage the students in a creative process that appeals to most liberal arts students. By building robots with certain capabilities but no prescribed design, liberal arts students should feel comfortable indulging their creativity in designing their robots. The use of familiar Lego bricks should help make the technical side of this process accessible.

Robotic design is very similar to two subjects already familiar to most liberal arts students: music composition and creative writing. Both subjects require the student to become familiar with a new set of vocabulary, a set of basic building blocks (notes or chords in music, words and phrases in literature), and the rules for combining the building blocks. The student then uses the knowledge to create something new and different.

We will employ science fiction short stories in this course in order to motivate student interest, establish some context, and help students get into the mindset necessary for robot programming. To this end, we will read several short stories by Isaac Asimov.

Asimov was not a computer scientist and never programmed a robot in his life. Nevertheless, his robot stories emphasize that ontologically, robots are machines whose actions are dictated entirely by their programming. Furthermore, it is possible to predict 
future robot behavior (or explain past robot behavior) by methodically thinking through the interactions of the robot's program and the robot's environment. This thought process is a major theme of several of his robot short stories.

One of the best examples of such a story is "Runaround"17. In this story, a robot is running in circles on the surface of the planet Mercury and refusing to obey orders. Two stranded astronauts need to determine what has gone wrong with the robot and then regain control of it.

The astronauts attempt to reason about the behavior of this wayward robot in terms of its fundamental programming: the Three Laws of Robotics. The laws are:

1. A robot must never harm a human being nor through inaction allow a human being to come to harm.

2. A robot must obey all orders from a human being, unless those orders conflict with the first law.

3. A robot must preserve its own existence, unless doing so conflicts with either the first or second law.

The astronauts find it difficult, at first, to determine the source of the robot's refusal to obey their orders, given the high priority the Three Laws place on such directives. By the end of story, however, the astronauts have determined the cause of the robot's misbehavior in terms of this fundamental programming.

This story emphasizes the "detective work" flavor of finding bugs in computer programs. Beginning programming students easily become frustrated when their programs fail to work, and in part it is because they have not learned the detective work mindset necessary for finding bugs. We are interested to see if exposure to this mindset in the form of fiction might be helpful in teaching students the bug-finding mindset, and making this mindset more accessible to liberal arts students specifically.

\section{Conclusions}

The broader impact of this course centers on the intended audience: the liberal arts student. There have been a few robotics design courses designed for the liberal arts student, one of which is our model course. However, most of these classes are still aimed at the science major student. Hendrix College wishes to use the non-intimidating, flexible, and stimulating resources of the Lego Mindstorm product to gently introduce the nonscience major to programming, mechanics, the design process, problem solving, and the application of the scientific method.

There has been recent participation from several Little Rock and Conway area schools in the FIRST Lego League competition. The authors plan to offer mentoring services and encourage the course students to become involved in the area teams. Eventually, a servicelearning component may be added to this course. The service would be the mentoring of a 
local Lego League team.

This course will provide an enhanced learning environment at Hendrix College and in Arkansas. Historically, Arkansas has been one of the poorest states in the nation in technology education. Programs such as EPSCoR and FIRST have helped to enrich the technology education in Arkansas at the high school and graduate school levels. This course will help the motivated liberal arts student population in Arkansas. Through widespread dissemination, the authors also hope to impact the national community of liberal arts colleges.

\section{BIBLIOGRAPHY}

1. Lego Mindstorms http://mindstorms.lego.com

2. Hendrix College 2002 Catalog http://www.hendrix.edu/catalog/0203Catalog/0203CatalogSiteMap.htm

3. F. Turbak and R. Berg, "Robotic Design Studio: Exploring the Big Ideas of Engineering in a Liberal Arts Environment", Journal of Science Education and Technology.

4. Wellesley College Robotics Design Studio http://cs.wellesley.edu/rds

5. Martin, F., "The Handy Board" http://www.handyboard.com/

6. University of Arkansas SYEN 1305 "Introduction to Engineering" http://theduchy.ualr.edu/classes/syen1305/syllabus.html

7. FIRST: For the Inspiration and Recognition of Science and Technology http://www.usfirst.org

8. A. B. Wright and A. M. Wright, "FIRST in Engineering: a Service-learning Approach to Mechanical Design", Proceedings of the 2002 American Society for Engineering Education Annual Conference, Session 2002-109.

9. Meeden, L., "Using Robotics as an Introduction to Computer Science", In Proceedings of FLAIRS-96, http://www.cs.swarthmore.edu/ meeden/flairs96.html

10 .Young, J. F., "ELEC 201: Introduction to Engineering Design" http://www.owlnet.rice.edu/ elec201/

11 .MIT's 6.270 Autonomous Robot Design Competition http://www.mit.edu:8001/courses/6.270/home.html

12 .BrickOS: Lego operating system. http://brickos.sourceforge.net

13 .leJOS: Java for the RCX http://www.lejos.org/

14 .Brooks, R. A., "A Robust Layered Control System for a Mobile Robot”, IEEE Journal of Robotics and Automation, RA-2:1 (1996), pp 14-23.

15 .Brill, F. Z., Wasson, G. S., Ferrer, G. J., Martin, W. N., "The Effective Field of View Paradigm: Adding Representation to a Reactive System", Engineering Applications of Artificial Intelligence, 11 (1998), pp 189-201.

16 .Bonasso, R. P., Firby, R. J., Gat, E., Kortenkamp, D., Miller, D. P., Slack, M. G., "Experiences with an Architecture for Intelligent, Reactive Agents", Journal of Experimental and Theoretical Artificial Intelligence, 9:2 (1997).

17 .Asimov, Isaac, “I, Robot”, Bantam Books, 1994. 
Biographical Information

DR. ANN WRIGHT is an Assistant Professor of Physics at Hendrix College. She has experience teaching physics and astronomy to non-science majors. Her research interests include measurement of physical properties of hybrid rockets for NASA. She has four years experience as a mentor for FIRST team 356.

DR. GABRIEL FERRER is an Assistant Professor in the Dept. of Mathematics and Computer Science at Hendrix College. His research interests include artificial intelligence and robotics. He has experience teaching introductory and advanced programming and artificial intelligence.

DR. ANDREW WRIGHT is an Associate Professor of Applied Science and Systems Engineering at UALR. He has taught several mechanical design courses at UALR, including some elements of Lego robot design. He is the head engineer for FIRST team 356. Prior to his tenure at UALR, he designed aircraft engine control systems in industry. 